\title{
De fio a pavio: a história da Inquisição Portuguesa revisitada
}

De pe a pa: la historia de la Inquisición Portuguesa revisitada

From start to finish: the history of the Portuguese Inquisition revisited

Du débout à la fin: l'histoire revisitée de l'Inquisition Portugaise

Georgina Silva dos Santos[1]

\section{MARCOCCI, Giuseppe; PAIVA, José Pedro. História da Inquisição Portuguesa (1536-1821). Lisboa: Esfera dos Livros, 2013. 608 p.}

N

os dias que correm, poucos temas da história moderna unem tão bem o interesse dos leitores acadêmicos ao gosto do grande público como a Inquisição. Em parte porque alguns comportamentos condenados pelo tribunal no passado ainda continuam sendo alvo de preconceitos e hostilidades - apesar de não serem mais punidos pela justiça comum —, em parte porque a historiografia dedicada ao assunto produziu obras singulares, inovadoras. Algumas responsáveis por uma verdadeira renovação metodológica, ${ }^{1}$ outras por demonstrarem o arcaísmo de certas práticas e discursos. ${ }^{2}$

A projeção dos estudos sobre Inquisição é, no entanto, fato recente. Deve-se, certamente, à conexão entre a pauta de reivindicações das minorias sociais e a evolução da própria disciplina histórica, mais sensível aos dramas raciais e étnicos, aos conflitos morais e às relações de gênero, a partir dos anos $1980 .{ }^{3}$ É o que se verifica na produção dos meios universitários e na grande imprensa luso-brasileira da época, em contraste com o longo jejum decretado a partir da instalação de regimes autoritários na Europa e na América Latina, que inibiram o desenvolvimento dos estudos iniciados em Portugal, ainda no século XIX.

Resenha recebida em 10 de março de 2014 e aprovada para publicação em 27 de abril de 2014

[1] Departamento de História da Universidade Federal Fluminense (UFF) - Niterói (RJ) - Brasil. E-mail: georginasantos@uol.com.br

\footnotetext{
'A obra de Carlo Ginzburg, um dos grandes expoentes da micro-história italiana, contribuiu de forma decisiva para popularizar os estudos sobre a Inquisição. Cf. O Queijo e os vermes - o cotidiano e as idéias de um moleiro perseguido pela Inquisição, São Paulo, Companhia das Letras, 1987 (Primeira edição: Turim, Einaudi, 1976).

¿É o caso, entre outros, da obra de Robert Mandrou, Magistrados e feiticeiros na França do século XVII, São Paulo, Perspectiva, 1979 (primeira edição: Paris, Librarie Plon, 1968).

${ }^{3}$ Em 1986, Laura de Mello e Souza defendia na Universidade de São Paulo sua tese de doutorado: Sabás e Calundus - feitiçaria, práticas mágicas e religiosidade popular no Brasil Colonial. Publicado no ano seguinte com o título O diabo e a Terra de Santa Cruz, o trabalho analisava o "catolicismo colonial", marcado por práticas e costumes sincréticos, de caráter ambivalente, partillhado por colonos portugueses, africanos, indígenas e degredados da Inquisição. Em fins da década de 1990, publicou-se a 12a edição de O Martelo das Feiticeiras. O manual, composto por inquisidores alemães, orientou a caça às bruxas no início da era moderna e tornou-se uma referência para os tratados de demonologia nos séculos seguintes. Cf. Laura de Mello e Souza, O diabo e a Terra de Santa Cruz - feitiçaria e religiosidade popular no Brasil Colonial, São Paulo, Companhia das Letras, 1987; Henrich Kramer; James Sprenger, malleus Maleficarum (O martelo das feiticeiras), Rio de Janeiro, Record; Rosa dos Ventos, 1997 [1484].
} 
Quando o grande historiador português Alexandre Herculano lançou História da origem e do estabelecimento da Inquisição Portuguesa (1854-1859), ${ }^{4}$ os ventos do liberalismo já haviam soprado forte nas terras de Portugal, abalando os valores que alicerçavam as instituições do Antigo Regime luso. A extinção do tribunal do Santo Ofício, ocorrida na sequência da Revolução do Porto (1820), contava então 38 anos e as certezas do passado mostravam-se incapazes de suportar estudos calcados em fontes arquivísticas com apurada crítica documental. ${ }^{5}$ Concebida para combater o ultramontanismo, o absolutismo papal e as entidades aferradas à sua manutenção, a obra de Herculano expunha as vísceras da política religiosa dos Estados confessionais católicos para alertar os perigos de um retrocesso. Mas também distinguia-se dos ensaios impressionistas que lhe antecederam por ser a primeira síntese sobre a criação da Inquisição lusa.

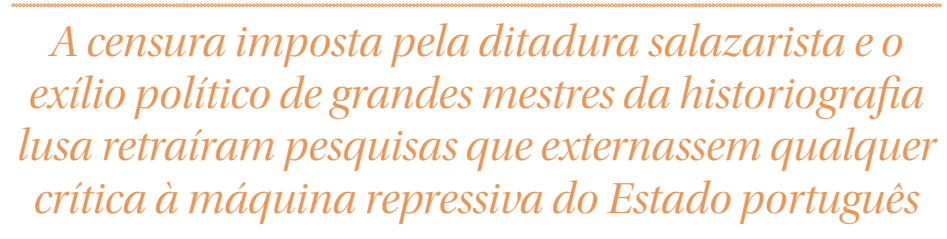

A competência de Herculano mostrou-se, todavia, insuficiente para mobilizar estudiosos contemporâneos com o intuito de coligir e interpretar as séries documentais produzidas pelo tribunal religioso. Por reconhecerem na Inquisição um capítulo vergonhoso da história portuguesa, muitos pesquisadores fecharam os olhos para a riqueza dos seus arquivos, preferindo empurrar para a penumbra atos e opiniões embaraçosos, condenando-os ao esquecimento. ${ }^{6}$ Foi preciso esperar pela centúria seguinte para ver multiplicar o interesse sobre a ação repressiva do Tribunal e conhecer o percurso acidentado dos réus enredados nas malhas da Inquisição. ${ }^{7} \mathrm{O}$ eco dessa alentada produção fez-se sentir também nas Américas, ${ }^{8}$ com a publicação de coletâneas documentais e estudos ancorados nos clássicos portugueses.

\footnotetext{
${ }^{4}$ Alexandre Herculano. História da origem e do estabelecimento da Inquisição Portuguesa, Lisboa, Bertrand, 1979 [1854-1859].

${ }^{5}$ História da origem e do estabelecimento da Inquisição Portuguesa surgiu no rastro da polêmica deflagrada com a edição da História de Portugal, também assinada por Herculano, que propôs, de acordo com os pressupostos do historicismo, uma nova interpretação para a formação do reino, até então calcada no Milagre de Ourique. Para desgosto do autor, ao invés de despertar o interesse pelo caráter inovador de sua abordagem, a tese tornou-se alvo de hostilidades, encobrindo a contribuição que trazia à historiografia. Cf. Luís Reis Torgal; José Amado Mendes; Fernando Catroga, história da História em Portugal (sécs. XIX-XX), Lisboa, Círculo de Leitores, 1996, p. 66-67.

${ }^{6}$ José Ribeiro Guimarães, Summario de Vária História, Lisboa, Rolland \& Semiond, 1874, p. 30.

${ }^{7}$ Escritos nas três décadas iniciais do século XX. Episódios dramáticos da Inquisição Portuguesa, de António Baião, e História dos cristãos-novos portugueses, de João Lúcio de Azevedo, integram hoje o rol dos clássicos sobre a história da atuação da Inquisição Portuguesa. Cf. António Baião, Episódios dramáticos da Inquisição Portuguesa, Porto, Edição da Renascença Portuguesa, 1919, 2 v.; João Lúcio de Azevedo, História dos cristãosnovos portugueses, Porto, Clássica, 1922.

${ }^{8}$ Refiro-me à publicação da primeira visitação do Santo Ofício à América portuguesa, organizada por Capistrano de Abreu (1922-1925), e à edição norte-americana de História dos marranos (1932), assinada por Cecil Roth. Cf. Capistrano de Abreu, Primeira visitação do Santo Ofício às Partes do Brasil pelo Licenciado Heitor Furtado de Mendonça. Confissões da Bahia (1591-1592), São Paulo, Paulo Prado, 1922; Cecil Roth, História dos marranos, Porto, Civilização, 2001 [1932].
} 
O surgimento do Estado Novo (1933-1974) atrofiou, porém, os brotos dessa reflexão, inibindo o aparecimento de novas monografias sobre o assunto. A censura imposta pela ditadura salazarista e o exílio político de grandes mestres da historiografia lusa retraíram pesquisas que externassem qualquer crítica à máquina repressiva do Estado português. Em contrapartida, as investigações sobre os Descobrimentos e a Restauração, que enalteciam o pioneirismo, o espírito de liderança e de conquista dos portugueses, ganharam espaço para valorizar a política colonialista de Salazar.

Nesses anos sombrios, o silêncio imposto pela ditadura emudeceu muitas vozes no torrão lusitano. $\mathrm{O}$ interesse sobre a ação persecutória e opressiva do Santo Ofício encontrou, entretanto, morada além-Pirineus e acendeu polêmica sobre a autenticidade do criptojudaísmo dos cristãos-novos, recolocando os estudos inquisitoriais na agenda acadêmica. ${ }^{9}$ Mas a historiografia portuguesa sobre a Inquisição avançou mesmo, a passos largos, na década seguinte à Revolução dos Cravos (1974), com a colaboração, inclusive, de historiadores brasileiros.

Concentrados até então nos meandros da fundação do Tribunal, na censura que impôs aos luminares do Renascimento e na perseguição que moveu contra os cristãos-novos de judeus, os estudiosos passaram a debruçar-se sobre outros credos e práticas criminalizados pelo Santo Ofício; ${ }^{10}$ puseram-se a investigar a formação e a ampliação de seus quadros funcionais; interrogaram-se sobre o enraizamento de suas ideias e valores; ${ }^{11}$ propuseram grandes reflexões sobre os vínculos entre os poderes eclesiástico e inquisitorial. ${ }^{12}$

O balanço crítico dessa vigorosa produção e as controvérsias provocadas pela atuação do Santo Ofício em Portugal são matéria de análise da História da Inquisição Portuguesa (1536-1821), de Giuseppe Marcocci e José Pedro Paiva, lançada em Portugal em 2013. O livro é de fato a primeira síntese sobre a atuação do tribunal religioso nos domínios do Império marítimo português desde sua origem até a sua desativação. Composta por 18 capítulos, distribuídos em 5 partes, a obra pretende "proceder a uma escrupulosa reconstrução" da ação do Tribunal, de modo a "oferecer um confiável depósito de informação e conhecimento, baseado na leitura crítica dos documentos e nos contributos interpretativos da melhor historiografia internacional".13

\footnotetext{
${ }^{9}$ A polêmica entre o erudito português Antônio José Saraiva e o linguista e historiador de origem alemã, radicado em França, Israel Salvator Révah, ganhou as páginas do Diário de Lisboa e teve repercussão internacional. O debate inflamado entre o intelectual lusitano e o professor do Collège de France foi publicado em António José Saraiva, Inquisição e cristãos-novos, Lisboa, Estampa, 1985 [1969], p. 213-291.

${ }^{10}$ Em Portugal, Francisco Bethencourt marcou época com o Imaginário da magia - feiticeiros, adivinhos e curandeiros em Portugal no século XVI, São Paulo, Companhia das Letras, 2004 [1987]. No Brasil, os livros de Laura de Mello e Souza, O diabo e a Terra de Santa Cruz, São Paulo, Companhia das Letras, 1986, e de Ronaldo Vainfas, Trópico dos pecados, Rio de Janeiro, Campus, 1989, tornaram-se grandes sucessos editoriais na altura e são, hoje, clássicos da historiografia nacional.

"Uma mostra da nova geração de historiadores brasileiros devotados ao tema encontra-se em Ronaldo Vainfas; Bruno Feitler; Lana Lage (orgs.), Inquisição em xeque: temas, controvérsias e estudos de caso, Rio de Janeiro, EdUERJ, 2006.

${ }^{12}$ Há anos, José Pedro Paiva dedica-se ao estudo dos poderes e/ou competências partilhadas entre a Inquisição e a Igreja. A título de destaque, cito aqui José Pedro Paiva, Bruxaria e superstição num país sem "caça às bruxas", Lisboa, Notícias Editorial, 1997, e __... Baluartes da fé da disciplina - o enlace entre a Inquisição e os bispos em Portugal (1536-1750), Coimbra, Imprensa da Universidade de Coimbra, 2011. ${ }^{13 G i u s e p p e ~ M a r c o c c i ; ~ J o s e ́ ~ P e d r o ~ P a i v a, ~ H i s t o ́ r i a ~ d a ~ I n q u i s i c ̧ a ̃ o ~ P o r t u g u e s a ~(1536-1821), ~ L i s b o a, ~ E s f e r a ~ d o s ~}$ Livros, 2013, p. 13
} 
A parte I, "Inquisição e Renascimento - da gênese à primeira grande crise (1536-1605)", analisa as primeiras seis décadas de ação da Inquisição, isto é, o intervalo entre a data da fundação do Tribunal e a concessão do perdão geral outorgado pelo papa aos cristãos-novos por intermédio do rei Filipe II. No capítulo 1, os autores passam a limpo a versão do estabelecimento do Tribunal legada por Herculano, demonstrando, sem deixar nesga de dúvida, o protagonismo do Cardeal D. Henrique na formação e consolidação do aparato organizacional e financeiro da instituição.

Em seguida, atualizam o tema dos cristãos-novos, dialogando com a bibliografia especializada e servindo-se de vários processos inquisitoriais, assim como dos documentos do Conselho Geral do Santo Ofício. Ponderam que a "obsessão antijudaica" da Inquisição Portuguesa defrontou-se, inicialmente, com a resistência de erasmistas, mas venceu a batalha ideológica contra a evangelização pacífica dos judeus lançando monitórios, realizando autos de fé e implantando o sistema de delações cruzadas, que no caso dos consanguíneos, se revelou fundamental. Embora o foco da ação inquisitorial em Portugal tenha sido a repressão ao judaísmo, o Tribunal exerceu vigilância incansável sobre práticas e condutas dos cristãos-velhos, como observam Marcocci e Paiva no capítulo destinado ao assunto.

\section{Embora o foco da ação inquisitorial em Portugal tenha sido a repressão ao judaísmo, o Tribunal exerceu vigilância incansável sobre práticas e condutas dos cristãos-velhos}

Segundo os historiadores, entre os anos de 1536e 1605, a Inquisição redobroua atenção sobre erasmianos, luteranos, alumbrados, curandeiros, feiticeiras e sobre todos aqueles que mantinham comportamento sexual considerado pecaminoso, fossem bígamos, polígamos, concubinos ou homossexuais. Desempenhando uma tarefa antes confiada aos bispos, passou a monitorar também impressos e manuscritos. No rol dos gêneros condenados pelo Tribunal, constavam Bíblias em língua vulgar, escritos em hebraico, livros de origem muçulmana, assim como as obras de Lutero, de Calvino e aquelas sobre a arte da necromancia. O programa de patrulhamento da leitura e de censura da escrita baseava-se no controle sobre o comércio e a reprodução da lista de títulos proibidos pelo Concílio de Trento. Incluía visitas periódicas às livrarias e, como é sabido, o domínio sobre a concessão de licenças para impressão.

A primeira parte da História da Inquisição Portuguesa finda no capítulo 4, com a análise sobre a presença da Inquisição nos territórios do Império ultramarino. De acordo com os autores, ao alternar castigo e misericórdia nos processos formais, realizar visitações e reconciliações privadas, usar uma rede de familiares e comissários para se fazer representar e utilizar a colaboração de bispos e missionários, a Inquisição conseguiu difundir sua presença nos 
continentes americano, africano e asiático, a despeito de ter instalado apenas o Tribunal de Goa fora do espaço europeu.

A estruturação do aparato inquisitorial deu-se, no entanto, em etapas. O tribunal desenvolveu-se significativamente durante a dinastia Habsburgo, tempo no qual conheceu seu apogeu, mas também seu primeiro grande golpe. Quando a soberania lusa retornou às mãos portuguesas, em 1640, a máquina inquisitorial era uma instituição madura, com representantes e simpatizantes em todos os segmentos da sociedade. É sobre esse período que Marcocci e Paiva ocupam-se na segunda parte da obra em tela.

"O Santo Ofício entre duas dinastias: do apogeu à suspensão (1605-1681)" demonstra a profunda ligação entre a conjuntura de ascensão dos Filipes em Portugal e o crescimento da receita inquisitorial, de seus quadros funcionais e o aperfeiçoamento de seus regulamentos internos. Ancorados em estudos de ponta e larga referência documental, Marcocci e Paiva revelam que o Santo Ofício transformou-se, nessa época, em um "viveiro de recrutamento" ${ }^{14}$ usado para preencher grandes cargos da Igreja, dos tribunais e dos conselhos régios. Mostram a paulatina ingerência da Inquisição na averiguação das infrações originalmente sob a alçada da justiça eclesiástica, como o julgamento dos religiosos que cometiam o crime de solicitação no confessionário, ${ }^{15} \mathrm{e}$ sua gradativa intervenção nos delitos de foro misto, ou seja, nos casos em que a competência do julgamento cabia tanto à justiça régia quanto à episcopal, como nas acusações de bigamia e feitiçaria.

O crescimento do poder inquisitorial chocou-se, entretanto, com os interesses do poder régio algumas vezes, como salientam os historiadores. Em 1627, para contornar séria crise financeira, a Coroa favoreceu o ingresso de cristãosnovos em ordens militares e concedeu-lhes licença para negociar no Oriente, em troca de empréstimos monetários. Embora muito significativo, o episódio não refreou a perseguição aos cristãos-novos, que seguiu sem tréguas ao longo do século XVII, como explicam Marcocci e Paiva. A adoção cada vez mais alargada dos estatutos de limpeza de sangue pelas organizações civis e eclesiásticas compactuava com a ideologia excludente e racista da Inquisição.

Entre 1620 e 1674, período mais violento da história do Tribunal, leigos e religiosos suspeitos de "judaizar em segredo" foram levados aos cárceres. Mas também os simpatizantes das vítimas, que discordavam dos métodos de repressão inquisitorial, como o célebre António Vieira, partidário dos casamentos mistos, defensor da instrução da fé católica aos conversos e crítico do confisco indiscriminado dos seus bens. As acusações feitas a Vieira baseavam-se, outrossim, em suas proposições de inspiração messiânica. Em sermões para a Corte e em outras audiências, o padre pregara a ressurreição do rei D. João IV para consumar o "Quinto Império" português, como demonstram Marcocci e Paiva em ótimo capítulo destinado ao processo do jesuíta.

${ }^{14}$ Giuseppe Marcocci; José Pedro Paiva, História da Inquisição Portuguesa (1536-1821), Lisboa, Esfera dos Livros, 2013, p. 139.

15/dem, Ibidem, p. 145 
O embate entre Vieira e a Inquisição serve de mote para que os autores examinem com perícia a suspensão das atividades do Tribunal pelo papa, na sequência das denúncias encaminhadas pelo cristãos-novos à cúria romana, questionando os procedimentos usados pelo Santo Ofício na hora de extrair a confissão dos réus e a justeza das sentenças aplicadas aos condenados.

A análise dos percalços da Inquisição prossegue no capítulo oito, que aborda desafios e desacertos do Santo Ofício na Índia e abre caminho para a matéria da antepenúltima seção: a "Inquisição Barroca: em busca de um novo caminho (1681-1755)". Nesses capítulos, os autores discutem as condições impostas no Breve Pontifício para a reabertura do Tribunal e suas consequências para o ritmo da marcha persecutória da Inquisição. Realçam que, a despeito da redução no número de relaxados, da quantidade dos condenados e até da adoção de formas mais brandas de tortura, a fase barroca do Tribunal foi caracterizada pelo enraizamento social do ideário inquisitorial. Em outras palavras, a assimilação dos critérios de estratificação racial definidos pelo Santo Ofício superou a preocupação estritamente religiosa que definira a instalação do Tribunal no Quinhentos.

\section{O embate entre Vieira e a Inquisição serve de mote para que os autores examinem com perícia a suspensão das atividades do Tribunal pelo papa}

Não obstante, o lema da Inquisição, "misericórdia e justiça", manteve-se inalterado, tal e qual a performance dos autos de fé, espetáculo concorridíssimo que atraía interesses diversos. A caminho do século XVIII, o combate às heresias em território metropolitano incidia, todavia, na repressão ao molinosismo, ao sigilismo e à maçonaria. Nas partes do ultramar, as sentenças seguiam o repertório de sempre, como apontam Marcocci e Paiva no capítulo 12: "A pressão nos trópicos: a atração pelo Brasil". Mas a polarização cada vez maior entre a dimensão atlântica e a porção oriental da Inquisição, flagrante na redução das perseguições na América portuguesa em contraste com a volumosa repressão na Índia, dava sinais da fragilidade institucional do Tribunal.

O progressivo declínio da Inquisição é o foco dos historiadores na parte IV da obra resenhada: "Um Tribunal dominado - da Reforma Pombalina à decadência". O uso da máquina inquisitorial pelo Marquês de Pombal para calar desafetos e adversários políticos explica, segundo os autores, os episódios emblemáticos que marcaram os últimos tempos da Inquisição Portuguesa, nomeadamente a execução dos Távoras e a do jesuíta italiano Gabriel Malagrida. Porém, o protagonismo do primeiro ministro de D. José na condução da política do reino afetou realmente a identidade do Tribunal ao suprimir a distinção entre cristão-novo e cristão-velho em 1773. A nova 
versão do regimento da Inquisição, composta um ano depois, implicou a redefinição das práticas de delação e criminalização dos suspeitos, uma vez que a acusação em segredo passou a ser definitivamente proibida. Abalado estruturalmente, como demonstram os historiadores na última parte da obra, "O ocaso da Inquisição, da extinção à história”, o Santo Ofício sucumbiu às ideias liberais que animavam o cenário político português. Como revelam os dados trazidos pelos pesquisadores, deixou-se vencer porque já não contava com adeptos e simpatizantes. Pouquíssimos desejavam ser familiares e servir ao Tribunal em "negócios de segredo e importância", exibindo a limpeza do seu sangue.

Em síntese, História da Inquisição Portuguesa é título imprescindível para iniciantes e iniciados nos assuntos do Tribunal religioso. A par de um excelente caderno de imagens, concentra um impressionante conjunto de informações fatuais, bibliográficas e documentais, tratadas criticamente. Talvez bastasse dizer que leva as assinaturas de Giuseppe Marcocci e de José Pedro Paiva, garantias de qualidade e competência. 